Original Article (short paper)

\title{
Influence of Adventure Race Disciplines on the Overall Performance during 35 to 50-km Races
}

\author{
Bruna Santana Silva $^{1}$ (D) , Claudio Alexandre Gobatto ${ }^{1}$ (D) , Fúlvia de Barros Manchado-Gobatto ${ }^{1}$ (i) , Larissa Mayara \\ Pereira Sulinski ${ }^{1}$ (D) , Taisa Belli ${ }^{1}$
}

${ }^{1}$ Universidade Estadual de Campinas, Faculdade de Ciências Aplicadas, Laboratório de Fisiologia Aplicada ao Esporte, Limeira, SP, Brasil

\begin{abstract}
Aims: This study aims to analyze the influence of adventure race disciplines on the overall performance during 35 to 50-km competitions. Methods: Twenty-four athletes from twelve teams were studied during the second (Jacarei-SP, Brazil, 44.5-km) and fourth (Passa Quatro-MG, Brazil, 37.1-km) races of the 2015 Haka Race Series, which comprised Brazilian Adventure Race Ranking. We analysed the relationship between disciplines velocities and overall race velocity of the teams during each competition. Results: We observed the race velocity of the teams during second race was significantly $(\mathrm{P}<0.05)$ correlated with the first $(\mathrm{R}=0.80)$ and last $(\mathrm{R}=0.65)$ split velocities of trekking, and with the last split velocity of mountain biking $(\mathrm{R}=0.73)$. On the other hand, the race velocity of teams during fourth race was significantly $(\mathrm{P}<0.05)$ correlated with the split velocity performed during the course of water trekking with trekking $(\mathrm{R}=0.96)$. Conclusion: Greater performance of the athletes in the disciplines of mountain biking, trekking and water trekking is related to their overall performance during 35-50 km ARs. In addition, the influence of adventure race disciplines is specific to the overall performance during different competitions.
\end{abstract}

Keywords: adventure race, mountain biking, trekking, performance

\section{Introduction}

Adventure racing (AR) is an ultra-endurance competition that is growing in popularity, with increasing numbers of events and participants around the world. ARs are held in natural environments (off-road trails, watercourses, coast, mountains, and paths), and athletes performed the competition by orienteering. Races are categorised by duration from sprint races ( $<6$ hours) to expedition races ( $36 \mathrm{~h}$ to 10 days) and comprise multiple outdoor sports disciplines, including mountain biking, trekking, kayaking, caving, technical climbing and fixed-line mountaineering ${ }^{1,2}$. Here we will focus on the relevance of the disciplines on the overall performance of the athletes during ARs.

Multiple factors influence the overall performance of the athletes during ultra-prolonged and multi-sportive competitions, including performance in split disciplines ${ }^{3}$. The knowledge about relative contribution of each discipline may thus to improve training prescription and race strategies, and to be decisive to the successful of the athletes during these competitions ${ }^{4-6}$. The most studies focused on the relevance of the disciplines on the overall performance during ultra-prolonged triathlon competitions $^{3,4,7}$. To our knowledge, Miorando Júnior, Castro, $\mathrm{Vaz}^{6}$ conducted an initial study to investigate the relevance of trekking and mountain biking during a simulated AR. The race comprised just these two disciplines, with the course guided by arrows (i.e., without map reading and navigation). They observed significant relationships between overall race time and mountain biking split time, while the trekking discipline were not related to the overall performance during the competition.

We emphasize, however, that the official AR format is not predetermined as observed in triathlon, or even as occurred in the aforementioned simulated AR. The sequence of disciplines in the AR and the total distance of each discipline may vary with each competition. Besides, the total distance of each discipline is not normally traveled at one time, but fractional throughout the race. Additionally, the course is often disputed in inhospitable regions of intimate contact with nature ${ }^{1,8,9}$. Thus, adventure racers face distinct demands on each competition, which can lead to specific relevance of the disciplines to the overall race performance.

Based on the above statements, this study aimed to analyze the influence of adventure race disciplines on the overall performance of the athletes in two official competitions of 35 to $50 \mathrm{~km}$.

\section{Methods}

\section{Participants}

Twenty-four athletes from twelve teams (18 males and 6 females) were studied in the second race of the 2015 Haka Race Series, during the last week of May, in the city of Jacarei 
(Sao Paulo, Brazil). Moreover, fourteen of these athletes from seven teams (11 males and 3 females) were also evaluated during the fourth race of the 2015 Haka Race Series, during the second week of November, in the city of Passa Quatro (Minas Gerais, Brazil). Volunteers were moderately to well- trained, experienced in long distance sports (a minimum of two years of AR experience), and completed the races without or with minimal navigation errors. This study was approved by the local research ethics committee (CAAE $\mathrm{n}^{\circ}$ 32175414.3.0000.5404). All participants were informed of the research procedures and purposes of the investigation and gave their written consent prior to participation. Athletes' characteristics are showed in Table 1.

Table 1 - Physical characteristics, body composition and training status of participants.

\begin{tabular}{ccc}
\hline & $\begin{array}{c}\text { Second race (Jacarei/SP) } \\
(\mathbf{n = 2 4 )}\end{array}$ & $\begin{array}{c}\text { Fouth race (Passa Quatro/MG) } \\
(\mathbf{n}=\mathbf{1 4})\end{array}$ \\
\hline Age (years) & $38.6 \pm 1.5$ & $39.4 \pm 1.3$ \\
Height (cm) & $171.4 \pm 1.7$ & $172.0 \pm 2.1$ \\
Body weight (kg) & $74.3 \pm 3.3$ & $73.4 \pm 3.3$ \\
Body mass index (kg/m $\left.{ }^{2}\right)$ & $25.4 \pm 0.8$ & $24.7 \pm 0.7$ \\
Fat-free mass (kg) & $34.3 \pm 1.6$ & $34.4 \pm 1.9$ \\
Fat mass (kg) & $13.9 \pm 0.9$ & $13.3 \pm 0.9$ \\
Fat mass (\%) & $18.6 \pm 0.8$ & $17.0 \pm 0.9$ \\
AR experience (years) & $4.8 \pm 0.7$ & $4.8 \pm 1.0$ \\
IPAQ (METs) & $3222.8 \pm 336.4$ & $3626.0 \pm 235.9$ \\
Running volume (km/week) & $17.3 \pm 4.3$ & $21.2 \pm 6.6$ \\
Mountain bike volume (km/week) & $46.5 \pm 7.5$ & $42.7 \pm 7.1$ \\
\hline
\end{tabular}

$\mathrm{AR}=$ Adventure race; IPAQ= International Physical Activity Questionnaire.

\section{Haka Race Series description}

Haka Race is an annual series of four adventure races included in the Brazilian Ranking of ARs. Competitions range from 35 to $50 \mathrm{~km}$, and athletes of both sexes may participate as individuals (solo) or in teams (pairs or quartets). Races comprise multiple outdoor sports disciplines, and usually including mountain biking, trekking, kayaking and ropes courses performed in a variety of terrains (off-road trails, watercourses, coast, mountains, and paths) by orienteering (map and compass navigation). The route is only revealed the day before or the day of the start when the participants receive the topographic map of the region and the race book with the geographic coordination of each mandatory stop between start and finish. The team must pass all compulsory control points (CPs) and transition areas (TAs) in the specified discipline to cross the finish line as an official finisher. Failure to fulfil the competition requirements results in penalties and elimination.

\section{Research design}

Athletes completed a questionnaire on basic demographic and characteristics of training, answered the International Physical Activity Questionnaire (IPAQ) (Fogelholm et al. ${ }^{10}$ ), and underwent body composition evaluation (Inbody 120; Biospace Co., Seoul, Korea) before the race. Race books, topographic maps, split and overall race times were recorded by official race reports. Analysis from these data was conducted later, at laboratory conditions to verify athletes' performance during the competitions.

\section{Races and performance analysis}

First, we verified the sequence of disciplines of each competition via race books. Then, split and overall distances were assessed by two independent navigators via topographic maps reading, and determined as the average of these two evaluations for each race. Records of split and overall race times were obtained by the official race reports. Thus, we calculated split and overall velocities of athletes' teams as performance indexes. Moreover, we estimated the relative contribution of each discipline to the overall distance and race time during the competitions.

There was no record of split time in the last TA (trekking to mountain biking transition) during the second race of 2015 Haka Race Series (Jacarei/SP), thus we took on the split time of the next CP to verify the performance during the last course of mountain biking. Moreover, there was no record of split time at water trekking to trekking transition during the fourth race of 2015 Haka Race Series (Passa Quatro/MG), thus, we analyzed the performance of these disciplines together. 


\section{Statistical analysis}

Normal distribution and homogeneity of the data were verified by the Shapiro-Wilk test and Levene's test, respectively. Pearson's correlation coefficient was used for analyzing the possible relationship between disciplines velocities and overall race velocity of the teams. Statistical significance was set at $P$ $<0.05$. Data were expressed as the mean and standard error of mean (SEM). Statistical procedures were carried out using Statistic 7.0 (Statsoft, Tulsa, USA).

\section{Results}

The second race covered a total of $44.5 \mathrm{~km}$, whereas the fourth race covered a total of $37.1 \mathrm{~km}$. The course elevation ranged from 600 to $700 \mathrm{~m}$ and from 1000 to $1700 \mathrm{~m}$ during the second and fourth races, respectively. Volunteers finished the second ( $\mathrm{n}=12$ teams) and fourth $(\mathrm{n}=7$ teams) competitions with a race time of $4 \mathrm{~h}$ and $31 \mathrm{~min} \pm 10 \mathrm{~min}$ and $9 \mathrm{~h}$ and $13 \mathrm{~min} \pm 27 \mathrm{~min}$, respectively. Race time of all the athletes that finished these competitions varied from $3 \mathrm{~h}$ and $45 \mathrm{~min}$ to $07 \mathrm{~h}$ and $29 \mathrm{~min}$ in the second race (Jacarei/SP) $(\mathrm{n}=62$ teams), and from $6 \mathrm{~h}$ and 5 $\min$ to $12 \mathrm{~h}$ and $30 \mathrm{~min}$ in the fourth race (Passa QuatroMG) ( $\mathrm{n}=$ 33 teams).Relative humidity was $50-70 \%$ for both competitions, while ambient temperatures were $13-23^{\circ} \mathrm{C}$ and $22-31^{\circ} \mathrm{C}$ during the second and fourth race, respectively. The sequence and distances of disciplines, the performance of the athletes during the competitions (i.e., race times and race velocities), the relative contribution of each discipline to the overall distance and race time, and the correlation coefficients between split velocities and race velocities are illustrated in Figure 1.

The second race (Jacarei/SP) started with mountain biking, followed to a course of trekking. The team were then divided, and while one of them performed a course of trekking the other one performed kayaking simultaneously. In the next course, the runner that performed a course of trekking performed kayaking while his/her partner performed a course of trekking with a rope course. Afterward, the team followed together by a path of trekking and finished the race by a course of mountain biking. The fourth race (Passa Quatro/MG) was composed by a sequence of mountain biking, trekking with a rope course, water trekking, trekking and mountain biking.

We observed the race velocity of the teams during second race (Jacarei/SP) was significantly correlated $(\mathrm{P}<0.05)$ with the first and last split velocities of trekking, and with the last split velocity of mountain biking. On the other hand, the race velocity of teams during fourth race (Passa Quatro/MG) was significantly correlated with the split velocity performed during the course of water trekking with trekking.



Figure 1 - Race characteristics, performance of the athletes, and the correlation coefficients between disciplines velocities and overall race velocity during the second race (Jacarei/SP) (A) and the fourth race (Passa Quatro/MG) (B). 


\section{Discussion}

To our knowledge, this study is a pioneer in investigating the relevance of disciplines in official AR competitions. Our main findings showed that the split performance of the athletes during the disciplines of mountain biking, trekking and water trekking was related to their overall performance. Moreover, the influence of the disciplines was different for second and fourth race of the 2015 Haka Race Series.

The results presented here extend those observed by Miorando Júnior, Castro, $\mathrm{Vaz}^{6}$, which mountain biking was the most relevant discipline for the performance of six experienced athletes competing for a simulated AR comprised mountain biking and trekking. Here, the mountain bike discipline had a predominant accumulated distance, representing about $60 \%$ of total distance of the competitions. However, the relative contribution of courses that included trekking was predominant for the race time, representing around 60 to $75 \%$ of the races. In addition, split velocities of mountain biking, trekking and water trekking were significantly correlated with overall velocities of the races. Our findings corroborate the data observed in ultraprolonged triathlon competitions (i.e., lasting more than 4 hours), in which the split time of cycling and running correlate with the overall race time $e^{7,11,12}$, with each of these disciplines contributing around of $40 \%$ for the race time of the triathletes ${ }^{4}$. We suggest, therefore, that both mountain biking and trekking and water trekking can decisively influence athletes' performance in official AR competitions.

The influence of the disciplines was specific for each AR race studied. In the Jacareí/SP competition, split velocities of trekking and split velocity of last course of mountain bike were associated with the overall race velocity. On the other hand, in the Passa Quatro/MG race, the overall race velocity was related with the split velocity of water trekking/trekking, without significant correlations with the mountain bike trails. These results add to those observed by Leite, Urtado, Donatto, Prestes, Salles, Borin, Pessoa Filho ${ }^{13}$, who studied the influence of disciplines throughout a season of the Brazil Triathlon Trophy. The authors reported the running was the discipline that had higher influence in overall performance during two races placed in Santos/SP, swimming and cycling were decisive disciplines in the competition in Rio de Janeiro/RJ, whereas running, cycling and swimming had similar influence to the overall race performance in Nova Lima/MG.

The split velocity of the last course of mountain bike was positively related to the overall performance of the adventure racers competing in Jacarei/SP. Studies showed that the residual effect of the previous exercise can cause an increase in the physiological demand in the subsequent exercise, causing a possible decrease in performance ${ }^{14-16}$. Therefore, the intensity of the previous disciplines may have impacted the performance of the studied athletes in the last course of mountain biking and influenced their final performance in the second race of the Haka Race Series. In the Passa Quatro/MG race, performance in the courses of water trekking/trekking was decisive for the performance of the athletes in the competition. We highlighted the athletes performed $55 \%$ of the race time $(5 \mathrm{~h} 07 \mathrm{~min} \pm 23$ min) to complete $16.9 \%$ of the distance of the race $(6.3 \mathrm{~km})$ during this course, predominantly in the middle of a course of water with stones. In this way, the athletes who were more able to move in this difficult terrain, with high demands of orientation/ navigation, thermal and emotional stress were the best placed in the competition. This race was held in a terrain varying from 1000 to $1700 \mathrm{~m}$ and, although the topographic maps did not provide enough information to determine a detailed elevation profile throughout the competition, it is plausible suppose the elevation changes also influenced the water trekking/trekking performance of the athletes. In addition, the studied races occurred at different times of the year, which can lead the athlete to compete in different phases of their annual preparation and, consequently, influence the relevance that each discipline can have for the success in each competition over a season ${ }^{13}$. Higher ambient temperatures values were also observed during the fourth (held in spring season) compared to the second (held in autumn season) race, which was possibly another factor that influenced our outcomes.

A limitation of this study was the lack of split time record in one TA of each studied race. Moreover, studied races structures did not allow us to analyse the specific influence of kayaking and rope courses on the overall performance of the athletes. Futures studies may focus on this issue. Participation of mixed teams (men and women) as subjects of this investigation could be considered another limitation, however, this is in accordance with the characteristics of official ARs.

\section{Conclusion}

Greater performance of the athletes in the disciplines of mountain biking, trekking and water trekking is related to their overall performance during $35-50 \mathrm{~km}$ ARs. In addition, the influence of adventure race disciplines is specific in different competitions, and may be influenced by the residual effect of the previous disciplines, the relative contribution of each discipline to the overall race time as well as the degree of difficulty of the terrain. Practical implications for coaches can be to use this knowledge to design the training and race strategies in different competitions throughout the season. Coaches may explore a range of tactical-technical and physical competencies in the disciplines of trekking and mountain biking during the training sessions, including the most diverse terrains (e.g., mountains, river, etc.), in order to prepare the adventure racers for high performances in different competitions. Furthermore, adopting pacing strategies to minimize the residual effect in the last disciplines may also be an advantageous race strategy during AR events.

\section{References}

1. Levada-Pires AC, Fonseca CE, Hatanaka E, Alba-Loureiro T, D'Angelo A, Velhote FB, et al. The effect of an adventure race on lymphocyte and neutrophil death. Eur J Appl Physiol. 2010;109(3):447-453. 
2. Townes DA. Wilderness medicine: strategies for provision of medical support for adventure racing. Sports Med. 2005;35(7):557-564.

3. Knechtle B, Knechtle R, Stiefel M, Zingg MA, Rosemann T, Rust CA. Variables that influence Ironman triathlon performance - what changed in the last 35 years? Open Access J Sports Med. 2015;6:277-290.

4. Figueiredo P, Marques EA, Lepers R. Changes in Contributions of Swimming, Cycling, and Running Performances on Overall Triathlon Performance Over a 26-Year Period. J Strength Cond Res. 2016;30(9):2406-2415.

5. Etxebarria N, Anson JM, Pyne DB, Ferguson RA. High-intensity cycle interval training improves cycling and running performance in triathletes. Eur J Sport Sci. 2014;14(6):521-529.

6. Miorando Júnior M, Castro FS, Vaz MA. Relevance of trekking and mountain bike for the performance at adventure races. Revista de Educação Física. 2008;142:5-11.

7. Carmo EC, Ramos HA, Elias L, Alves VT, Ugrinowitsch C, Tricoli VAA, et al. Performance analysis of elite Brazil-Ironman athletes from 2003 to 2010. Rev Bras Educ Fís Esporte. 2014;28(1):57-64.

8. Lucas SJ, Anglem N, Roberts WS, Anson JG, Palmer CD, Walker RJ, et al. Intensity and physiological strain of competitive ultra-endurance exercise in humans. J Sports Sci. Mar 2008;26(5):477-489.

9. Tossige-Gomes R, Ottone VO, Oliveira PN, Viana DJS, Araujo TL, Gripp FJ, et al. Leukocytosis, muscle damage and increased lymphocyte proliferative response after an adventure sprint race. Braz J Med Biol Res. Jun 2014;47(6):492-498.

10. Fogelholm M, Malmberg J, Suni J, Santtila M, Kyrolainen $\mathrm{H}$, Mantysaari M, et al. International Physical Activity Questionnaire: Validity against fitness. Med Sci Sports Exerc. 2006;38:753-60.

11. Knechtle B, Duff B, Amtmann G, Kohler G. Cycling and running performance, not anthropometric factors, are associated with race performance in a Triple Iron Triathlon. Res Sports Med. Oct-Dec 2007;15(4):257-269.

12. Knechtle B, Kohler G. Running performance, not anthropometric factors, is associated with race success in a Triple Iron Triathlon. $\mathrm{Br}$ J Sports Med. Jun 2009;43(6):437-441.

13. Leite GS, Urtado CB, Donatto FF, Prestes J, Salles FCA, Borin JP, et al. Sport performance in traithlon from a competition trials' analysis. Journal of Physical Education. 2006;17(1):37-43.

14. da Silva Neto LV, Smirmaul BPC, Pignata BH, Junior OA. Effect of swimming on the cycling and running performance during the super-sprint triathlon. J. Phys. Educ. 2014;25(1):45-51.

15. Pacheco AGL, Leite GS, Lucas R.D, Gugliemo L.G.A. The influence of swimming performance in triathlon: implications for training and competition. Rev Bras Cineantropom Desempenho Hum. 2012;14 (2):232-241.

16. Peeling PD, Bishop DJ, Landers GJ. Effect of swimming intensity on subsequent cycling and overall triathlon performance. Br J Sports Med. Dec 2005;39(12):960-964; discussion 964.

\section{Acknowledgments}

We would like to thank the volunteers, organizers and staffs of the "Haka Race Series".

Funding - The authors thank Fundo de Apoio ao Ensino, Pesquisa e Extensão - Pró Reitoria de Pesquisa - Universidade Estadual de Campinas (FAEPEX/ PRP/UNICAMP) (n. 1152/14) and Programa Institucional de Bolsas de Iniciação Científica/Conselho Nacional de Desenvolvimento Científico e Tecnológico/ Universidade Estadual de Campinas (PIBIC/CNPq/UNICAMP) for the financial support.This study was financed in part by the Coordenação de Aperfeiçoamento de Pessoal de Nível Superior - Brasil (CAPES) - Finance Code 001.

\section{Corresponding author}

Taisa Belli

Address: School of Applied Sciences, University of Campinas. Pedro Zaccaria Street, 1.300, Jardim Santa Luiza - Postal Code 13484-350 - Limeira - São Paulo - Brazil.

Email: taisa.belli@fca.unicamp.br

Editor: Angelina Zanesco, UNESP/Rio Claro, SP, Brazil

Manuscript received on September 4, 2019

Manuscript accepted on March 31, 2020

Legend:

(্ำ = Records of race time; $\mathrm{TA}=$ Transition Area; $\mathrm{CP}=$ Control Point

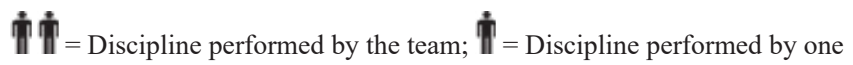
athlete;

= Rope Course performed by one athlete;

$\mathrm{MB}=$ Mountain Biking; $\mathrm{TK}=$ Trekking; $\mathrm{KAY}=$ Kayaking; $\mathrm{RC}=$ Rope Course; WT=Water trekking

$8 \mathrm{~km} *=5 \mathrm{~km} \mathrm{TK}+3 \mathrm{~km} \mathrm{MB} ; \mathrm{WT}^{*}=4.1 \mathrm{~km} ; \mathrm{TK}^{*}=2.2 \mathrm{~km}$;

$(\%)=$ Relative contribution of each discipline to the overall distance and race time.



Motriz. The Journal of Physical Education. UNESP. Rio Claro, SP, Brazil - eISSN: 1980-6574 - under a license Creative Commons - Version 4.0 